\title{
EL DESTINO DE LA DIVERSIDAd ÉTNICA: ENTRE EL RECONOCIMIENTO FORMAL Y LA FRAGMENTACIÓN SOCIAl ${ }^{1}$
}

\section{The Fate of Ethnic Diversity: between Formal Recognition and Social Fragmentation}

\section{José Eduardo Zárate $\mathrm{H}^{2}$}

Resumen: El objetivo de este trabajo es ofrecer un amplio panorama de las respuestas que las organizaciones indígenas han dado a las reformas jurídicas de las últimas décadas. Nos interesa mostrar que la diversidad de respuestas no se circunscribe a un proyecto político único, sino que están definidas, en gran medida, por las circunstancias históricas particulares en que las comunidades han construido su identidad.

Palabras clave: multiculturalismo, diversidad, autonomía, política de reconocimiento.

Abstract: The objective of this study is to present a broad panorama of the responses that indigenous organizations have given to juridical reforms in recent decades. Our main interest is to demonstrate that the diversity of their responses shows that they are not circumscribed by one, single political project but, rather, defined to a large extent by the

\footnotetext{
${ }^{1}$ Nota del editor: se respeta íntegramente el texto final que entregó el autor, con los dictámenes académicos atendidos.

${ }^{2}$ Maestro en Antropología Social por El Colegio de Michoacán y Doctor en Ciencias Sociales por CIESAS Occidente. Líneas de investigación: Sociedad, ideología y concepciones del Mundo. Proyecto: Trasnacionalización, etnicidad y movimientos emergentes en el centro de Michoacán. El Colegio de Michoacán. Correo electrónico: zarate@colmich.edu.mx Fecha de recepción: 1004 17; Fecha de aceptación: 150617.
}

(c) BY-NC-ND Páginas 183-204. 
particular historical circumstances in which those communities have constructed their identity.

Keywords: multiculturalism, diversity, autonomy, politics of recognition.

\section{Introducción}

Una de las paradojas más evidentes de la legislación nacional en materia indígena es que al escudarse en el interés público lo que provocó fue una mayor fragmentación social. La condición para que esta fragmentación no devenga en mayor desigualdad y se manifieste en disolución social es la aplicación del llamado "Estado de derecho". Es decir, la aplicación estricta de la ley evitaría que la multiplicidad se manifieste en mayor conflictividad. Sin embargo, desde que apareciera en nuestro horizonte político la alternancia y el pluralismo, las decisiones en relación a modificación de leyes o la aprobación de otras nuevas se ha tomado en función del cálculo político inmediato y de los acuerdos entre partidos en función de la siguiente elección. ${ }^{3}$

No obstante, el marco jurídico actual, permite la expresión de diferencias culturales y el ejercicio de prácticas de gobierno autónomas, hasta cierto nivel y bajo determinadas circunstancias - como el permiso para organizar guardias y policías comunitarias o incluso grupos de autodefensa, cuando la amenaza del crimen organizado es más que evidente- El hecho es que en las últimas décadas, desde que apareció la alternancia en el año 2000, con el gobierno de Vicente Fox, el juego político que se da al interior del congreso entre las principales fuerzas y coaliciones que lo controlan y el ejecutivo ha terminado por afectar seriamente al Estado de derecho. Las leyes que del poder legislativo emanan o están sobrecargadas de intereses particulares, o son una simple caricatura de lo que demandaba la sociedad, porque hasta ahí pudieron llegar los arreglos entre partidos.

\footnotetext{
${ }^{3}$ La prueba es Michoacán, donde desde la década de los noventa, existía la posibilidad de una ley indígena de avanzada, sin embargo, los pleitos entre partidos y sobre todo entre facciones al interior de los mismos partidos que alternativamente controlaron el congreso (PRD y PRI) impidieron su concreción.
} 
Luego de la reforma constitucional del año 2001, que tenía como antecedente las modificaciones al artículo cuarto constitucional de una década antes, se inició el proceso de promulgación de las llamadas leyes indígenas en la mayoría de las entidades de la república. Proceso que en algunos estados no ha concluido y que en la mayoría, hasta hace pocos años finalizó. Con estas acciones el Estado pretendió dar respuesta a las demandas de reconocimiento de las organizaciones - comunidades y pueblos - indígenas que habían crecido de manera notable durante los noventa, como parte de la efervescencia por la transición y la alternancia democrática. Con sus decisiones, los políticos subordinaron los reclamos al "interés nacional" y al fortalecimiento de las estructuras de gobierno establecidas, — que van del gobierno federal a los estados, municipios y comunidades y, en cuya participación intervienen los partidos políticos- por lo que decidieron no reconocer a las comunidades y pueblos indígenas como sujetos con derechos. Dejaron de lado una serie de novedosas propuestas, emanadas tanto de los Acuerdos de San Andrés como del Congreso Nacional Indígena (CNI), —referidas al reconocimiento de la soberanía de comunidades y pueblos indígenas-, que los hubieran dotado no solo de autonomía jurídica, sino de leyes que efectivamente les permitieran defenderse y hacer frente con recursos legales sobre todo a la violencia que se vive en muchas regiones, resultado de la acción de caciques autoritarios, empresas trasnacionales — sobre todo aquellas dedicadas a las actividades extractivas-y grupos del crimen organizado, en ocasiones coludidos. No obstante, como lo señalan algunos autores (Devilard y Baer, 2010: 35), los cambios en el discurso jurídico, de cualquier manera que sean, representan una invitación para la movilización o desmovilización de los agentes a que va dirigido. En este caso, la llamada Ley Indígena marcó ciertos límites para la acción autónoma de pueblos y comunidades, pero también abrió algunas posibilidades para expresarse y demandar reconocimiento diferenciado por parte del Estado que ahora "debe no solo de reconocer sino proteger y sancionar jurídicamente tales diferencias”, esa definición es lo que De la Peńa (1999: 25) ofrece de ciudadanía étnica, que como todo proceso social se manifiesta de diversas maneras. 
A inicio del presente siglo se aprueba la primera ley nacional en la que se reconoce a los pueblos y comunidades indígenas como "sujetos de interés público". Sin duda una concepción y legislación bastante limitada, que dejó en los estados su implementación en términos de la definición concreta de los posibles "beneficiarios", y de los alcances que puede llegar a tener el reconocimiento de "sujetos colectivos". Si bien en estados como San Luis Potosí (SLP) o Michoacán se les reconoce como "sujetos con derechos". En los años posteriores a la promulgación, la mayoría de los estados de la república empezarán a elaborar legislaciones indígenas, en algunos casos más para recibir recursos que por un convencimiento del congreso local. Como sucedió en Guanajuato, luego de que en la prensa nacional apareciera la nota de que el estado estaba dejando de percibir una buena cantidad de millones de pesos, por no contar con una ley indígena, en menos de una semana los diputados locales, se apresuraron a "redactar" y aprobar la Ley Indígena de Guanajuato. Por supuesto con muchas deficiencias, como que no dice nada sobre los indígenas migrantes que se asientan en las principales ciudades y que quizá constituyen la mayoría de la población indígena en el estado.

Como se recordará, durante la década de los noventa, —luego de las rupturas e impasse que habían causado en distintas organizaciones el proceso electoral de fines de los ochenta y sobre todo la implementación del Programa Nacional de Solidaridad-con el impulso del Ejército Zapatista de Liberación Nacional (EZLN) aparecen nuevas organizaciones con la demanda de la inclusión en primer lugar — "nuca más un México sin nosotros" — ${ }^{4}$. No se dejaban de lado los reclamos de respeto y reconocimiento de su territorio o tierras comunales, así como que se les consultara en los asuntos que a ellos concernía, sobre todo en la aplicación de programas sociales y obras públicas, demandas que estaban presentes en las organizaciones indígenas y campesinas de los años ochenta. Además se ampliaban al reconocimiento de sus sistemas normativos de gobierno, impartición de justicia y policía. Temas que

\footnotetext{
${ }^{4}$ El deterioro en las condiciones de vida de gran parte de la población rural, así como la pérdida de derechos sociales como los establecidos en el art. 27, que garantizaba la propiedad colectiva de la tierra a través de la figura del ejido, que se había reformado, conformaron el contexto en que aparece el levantamiento zapatista.
} 
de alguna manera estaban contemplados en los tratados internacionales que el Estado mexicano había signado en esa época de apertura al mundo global. A principios del siglo XXI, las expectativas creadas por la alternancia en el gobierno federal y la composición plural del congreso de la Unión en el que las llamadas "fuerzas" de la izquierda tenían una importante representación, provocaron que se viviera un momento de optimismo respecto al alcance de las reformas y en general que se pensara que se podría lograr una legislación "de avanzada". Por lo restringido de las reformas constitucionales, diferentes organizaciones indígenas calificaron de traición a los mismos representantes de los grupos de izquierda, que ni siquiera lucharon por una legislación más apegada a las demandas de las organizaciones indias, sino que se plegaron, como ocurre frecuentemente por negociaciones internas, a las propuestas de los partidos conservadores.

La década de los noventa fue un periodo de emergencia indígena (como lo llamó Bengoa, 2000) y en el que se hacen visibles distintas agrupaciones que habían mantenido "oculta" su identidad, aparecen múltiples organizaciones propiamente indígenas y en gran medida el movimiento se internacionaliza, sea mediante el vínculo con otras redes y organizaciones, sea mediante el uso de las nuevas tecnologías informáticas. ${ }^{5}$ Fue en las últimas dos décadas, del siglo XX, cuando aparecieron organizaciones y comunidades que desarrollaron procesos autonómicos de facto, en áreas como el gobierno local e incluso, en algunos casos, en lo referido a la seguridad y la impartición de justicia (como lo señala Sierra, 2006). Se esperaba que los cambios en el texto de la constitución abarcaran y legalizaran todos estos procesos. Si en los años setenta, los indígenas se hicieron visibles, en los noventa se harán evidentes, más que visibles y legibles. Es tan clara su presencia activa y sus reclamos de un reconocimiento ciudadano que lo que se discute es más bien "hasta donde pueden llegar" en términos de reconocimiento de derechos dentro del proyecto nacional. Es claro que había cierto optimismo, que se manifestaba en la celebración de congresos, encuentros, foros de discusión en los que se hacían propuestas, como la remunicipalización o la creación de regiones pluriétnicas autónomas.

\footnotetext{
${ }^{5}$ Aunque el antecedente internacional más claro son las reuniones de organizaciones indígenas celebradas en Barbados, en los años de 1971 y 1979.
} 
Un tema particularmente sensible era el de la impartición de justicia y el respeto a los derechos humanos, sobre todo en sociedades que, se decía no reconocían los derechos individuales (Vázquez, 2001). Pero también este reclamo adquiría relevancia en regiones donde el control de "hombres fuertes", caciques o de las organizaciones corporativas del partido oficial no dejaban espacio para manifestaciones y reclamos independientes. Temas que finalmente quedarían subordinados a la legislación nacional y que serán de especial competencia de la Comisión Nacional de los Derechos Humanos (CNDH).

Correspondería a los mismas entidades federativas darles respuesta - como ya venía sucediendo- a demandas como la creación o no de nuevos municipios, división y readscripción municipal, órganos propios de impartición de justicia, derecho de consulta o nuevos niveles de gobierno. El CNI se irá desintegrando poco a poco, aunque una pequeña parte sigue vinculada al zapatismo chiapaneco que se mantendrá como un referente importante de algunas comunidades y organizaciones, que incluso utilizarán el sobrenombre de "zapatistas". Este grupo evolucionará a lo que hoy se conoce como Consejo de Gobierno Indígena. A finales de mayo de 2017 propondrá a María de Jesús Patricio Martínez — conocida como "Mary Chuy" —, originaria de Tuxpan, Jalisco, como candidata independiente de los partidos políticos, para participar en las próximas elecciones presidenciales del año 2018. Con lo que esperan provocar la participación de gran parte de la sociedad civil que se encuentra ajena o cansada de los partidos políticos y de la política formal.

No obstante, la gran mayoría de organizaciones y comunidades aceptarán como principal interlocutor a los gobiernos de los estados, que son quienes finalmente aplican los programas sociales. Se podría decir que las comunidades indígenas pasaron de un momento de empoderamiento que las hizo visibles en las décadas de los ochenta y noventa a uno de normalización de una autonomía acotada. En el sentido no de que ya no persistan los conflictos y disputas o incluso de que puedan aparecer otros de carácter violento, sino de que esos deben resolverse dentro del marco jurídico vigente en el nivel de las entidades 
federativas y dentro del marco de competencia político interpartidista que define la composición de los congresos de los estados. Esto significa que si bien el reconocimiento es limitado, el ejercicio puede resultar muy diverso. En todo caso sus resultados pueden ser imprevisibles. De ahí también que algunos sujetos por el momento, no se propongan ir más allá de ciertas reivindicaciones, mientras que otros extienden la noción de autonomía a prácticamente todos o a la mayoría de los ámbitos de la vida social, incluyendo el gobierno por "usos y costumbres", la impartición de justicia —o de una justicia propia—y la aceptación o rechazo de ciertos programas o políticas sociales.

Se podría decir que a partir de las leyes indígenas en los estados de la república y de la elaboración y aplicación de los padrones de beneficiarios de los programas sociales dirigidos a la población indígena, entramos en la época del post reconocimiento que fue la discusión de los ańos noventa (como lo muestra el trabajo de Assies, et. al., 1999). Si bien, ahora no se discute más ese tema o se discute muy poco, dista de estar resuelto. A pesar de lo que se ha avanzado en el campo jurídico, en el aspecto sociológico queda mucho por hacer, no solo porque la segregación y la falta de oportunidades sigen vigentes en muchas regiones de nuestro país, sino porque continuamente aparecen nuevos escenarios donde se manifiestan de manera cruda estas prácticas segregacionistas. Tal es el caso de los jornaleros agrícolas que laboran en los campos del norte del país o en las zonas rancheras y que son sometidos a condiciones de vida ínfimas, legitimadas por un discurso racista, que se creía extinto en nuestro país. En su obra sobre la política del reconocimeinto Taylor (2009: 65), reconoce dos niveles: el íntimo y el público. Ambos se encuentran entrelazados. El segundo tiene que ver con las acciones propias del Estado hacia los sujetos individuales o colectivos que por sus particularidades se encuentran en desventaja. El primero, con el sujeto individual mismo y con la búsqueda de autenticidad, con el reconocimeinto social de su identidad. Está claro que hasta ahora las reformas jurídica han sido una respuesta débil, pero respuesta al fin, a las demandas de justicia y equidad que por décadas han manifestado las comunidades y pueblos indígenas, proceso que 
se continúa hasta nuestros días de dversas maneras. En este trabajo hablamos de post reconocimiento para referirnos a las respuestas de las mismas comunidades a las modificaciones al marco jurídico.

\section{Respuestas organizativas}

En lo que sigue, expondré a grandes trazos algunas respuestas que nos parecen indicativas de los rumbos que está tomando la diversidad en los últimos ańos. Aclaro que no pretendo dar cuenta de la totalidad de los múltiples y muy diversas respuestas que han dado los pueblos y comunidades indígenas a lo largo y ancho del país y luego de una década, sino solo destacar ciertas tendencias generales: la estrictamente política, la visualizadora o etnogenética $y$, la integrativa productiva o competitiva. Las tres implican ciertas formas de reorganización social y son de alguna manera respuestas a los procesos de diferenciación y exclusión del moderno sistema de integración global. A su vez tienen efectos diferenciadores en los mismos espacios en que se manifiestan. Estas grandes tendencias, en gran medida han sido definidas por las circunstancias históricas, en particular, por los problemas y conflictos que enfrentan las comunidades de cada región.

\section{Las autonomias radicales}

Aquellas comunidades que ya ejercían una autonomía de facto, que habían logrado procesos de organización autonómicos, bastante controlados y que esperaban una legislación de avanzada, han mantenido su rumbo sin considerar la particularidad de las leyes. Aquí se ubicarían las comunidades zapatistas. Hasta ahora no se conoce otra experiencia que rechace abiertamente la relación con el gobierno en cualquiera de sus niveles, ni que mantenga una distancia crítica con ciertos actores globales, sobre todo los relacionados con el mercado. Ya se ha escrito bastante sobre las comunidades zapatistas y su proyecto autonómico, solo se podría resaltar que para mantener su autonomía ha sido fundamental establecer un rígido sistema de impartición de justicia y de distribución del poder (Gasparello, 2014; Mora, 2013). ${ }^{6}$ De tal manera que su proyecto no presente fisuras ni rupturas a su

\footnotetext{
${ }^{6}$ Aunque lo que muestran los dos trabajos es lo limitado del campo de acción de las leyes revolucionarias y su aplicación.
} 
interior, que den lugar a la intervención externa. Esta es una tendencia que apunta a un fuerte control social que tiene su base en la coherencia entre el discurso basado en la justicia social la crítica de las políticas gubernamentales y la amplia participación y aceptación de la población local. Pueden surgir otros casos, pero también pueden debilitarse los existentes, precisamente cuando se percibe que se ha roto esa coherencia o los líderes no actúan conforme a lo que predican. En contraste, en Chiapas se presenta una de las legislaciones indígenas más escuetas del país. Sin embargo, hay que tener en cuenta que desde fines de los años noventa y principios del siglo actual se realizaron en la entidad cambios importantes que tenían que ver con los espacios de conflicto que estaban provocando inconformidad. Se reconocieron municipios que operaban de facto y se crearon otros nuevos (Leyva y Burguete, 2007). El estado se inundó de programas sociales, provenientes tanto de agencias internacionales, como del gobierno federal. Si bien no se reconoció la existencia de regiones autónomas, que era una de las demandas de las organizaciones indígenas chiapanecas, la división municipal —o "remunicipalización" — permitió el relajamiento de algunos viejos y nuevos conflictos, por ejemplo entre comunidades y ayuntamientos controlados por caciques mestizos. Estos importantes cambios hicieron intrascendente una ley indígena del estado como las que se aplicaron en las demás entidades: la remunicipalización y la instalación de las juntas de buen gobierno, se podría decir que fueron las respuestas desde las comunidades locales a la reforma legislativa.

Otros casos un tanto similares son San Juan Copala en Oaxaca y Cherán en Michoacán, San Juan Copala, se convirtió es una clara muestra de los efectos de las inconsistencias legislativas. Después de un amplio periodo de conflictos entre organizaciones políticas triquis de distinto signo partidista, pasó a ser un municipio autónomo, controlado por una organización triqui independiente. Posteriormente el municipio autónomo fue desmantelado y vuelto a controlar por grupos que se han impuesto con la fuerza de las armas, de la amenaza de ejercicio de la violencia y el discurso de "usos y costumbres". A mediados de la década actual, luego de la expulsión de familias enteras del municipio y del asesinato de opositores políticos, se vivía en la zona una situación 
crítica en el tema de los derechos humanos. Cherán, en Michoacán, ha mantenido cierta "autonomía", con base en el gobierno por "usos y costumbres”, sin rechazar la intervención del Estado. Es más, en los inicios del movimiento la demanda de que interviniera el ejército de manera decidida para controlar a las bandas del crimen organizado era clara. Aunque con grandes dificultades y presiones de los distintos partidos políticos, porque se abra, ha mantenido su sistema de gobierno desde 2011, con base en el Consejo Superior y la organización barrial. No está de más señalar que en Cherán, la búsqueda de financiamiento para el desarrollo de proyectos productivos, ahora vinculados a la recuperación del control del bosque comunal ha sido una constante.

\section{Visibilizados}

En el extremo opuesto estarían aquellas poblaciones que habían pasado desapercibidas, no habían sido consideradas en cuanto a su calidad étnica o, incluso, que trataban de ocultar su identidad $-\mathrm{o}$ de mimetizarse con su entorno mestizo- y que la legislación les permitió expresarse, sobre todo luego de participar en programas sociales. Aquí se observan claros procesos de etnogénesis, en el sentido de que se están señalando nuevas fronteras con base en categorías de adscripción, pero también de utilización o manipulación de su etnicidad para acceder a recursos. Una buena cantidad de estos grupos se encuentran en pequeñas localidades como ranchos y ejidos en las zonas rurales - en Jalisco, Michoacán, Guanajuato- Otra en las grandes y medianas ciudades. En éstas encontramos, por un lado, a los llamados "pueblos originarios" y, por otro, a los grupos de migrantes. Pequeñas comunidades ya plenamente integradas a la vida urbana —en la Ciudad de México, Guadalajara, Querétaro, SLP, Monterrey, Morelia, entre otros, pero que mantenían ciertas prácticas rituales, formas de organización familiar y religiosa o ciertos giros en el lenguaje- pudieron reconocerse como indígenas y ser consideradas en los padrones de beneficiarios. En algunas de estas ciudades, desde antes de la expedición de las leyes indígenas, la alternancia y la pluralidad política abrieron la posibilidad de beneficiar a una extensa población que no había sido considerada como étnicamente diferenciada. Además de otorgarles asesoría legal frente a prácticas 
excluyentes. Sin duda, han sido los gobiernos que se autodenominan como "de izquierda" en la Ciudad de México, los que desde los años noventa más recursos le dedicaron a los grupos indígenas de la ciudad, fueran originarios o migrantes residentes (Yanes, et.al., 2004).

En algunas regiones y ciudades han aparecido o reaparecido nuevas categorías de adscripción. En Michoacán, en particular, están los matlatzincas y pirindas, unos ahora integrados a la ciudad de Morelia y otros asentados en el oriente del estado (Paredes y Martínez, 2012), grupos étnicos que hasta hace una década se consideraban desaparecidos, si bien, en el vecino Estado de México mantienen una activa presencia. Casos similares se presentan en Querétaro, SLP, y por supuesto los llamados "pueblos originarios" de la Ciudad de México y de otras urbes. Pero también están los grandes grupos de indígenas migrantes que se asientan en las principales ciudades del país. Como Guadalajara, Monterrey, León, Guanajuato, Querétaro, Tijuana, San Cristóbal de las Casas, o la Ciudad de México. En algunos lugares las leyes indígenas reconocen explícitamente, los mismos derechos para esta población que para los "originarios", como en Michoacán o la Ciudad de México. En otros estados, como Guanajuato, no se reconocen a pesar de su notable presencia en las principales ciudades — como Guanajuato o León-y de que podrían resultar más numerosos que la población de algunas comunidades "originarias" o el caso de Monterrey, donde no había indígenas originarios.

Los casos de San Luis Potosí, Ciudad de México y ahora Morelia - donde recientemente se celebró un publicitado encuentro de comunidades matlatzincas - son notables, porque algunas de estas comunidades han logrado ciertos beneficios para sus comunidades de la cobertura que les ofrece la actual legislación y los canales de comunicación directos con el gobierno local para negociar proyectos colectivos tendientes a fortalecer su identidad. Un ejemplo es el de los nahuas asentados en Cuautepec en la Ciudad de México (estudiados por O. Leal, 2014). Un pequeño grupo nahua originario de Chilacachapa, Guerrero, que en las últimas décadas, sobre todo con los gobiernos perredistas de la ciudad y de la delegación, han obtenido, desde la regulación de sus terrenos, equipamiento urbano para su colonia, la construcción y operación de 
un centro cultural, donde incluso se enseña nahua, y la recuperación de un predio baldío para la edificación de un centro deportivo. Aunque tradicionalmente la consecución de obras públicas y la gestión exitosa de proyectos sociales ha significado el establecimiento de relaciones clientelares con alguna organización o grupo político, en algunos casos la nueva cobertura legal y el pluralismo político, les ha permitido negociar con mayor amplitud su compromiso y en ocasiones incluso negarlo a sabiendas de que no pueden ser excluidos totalmente de los programas sociales. Empero, la utilización clientelar de los programas sociales enfocados a los grupos marginados, sigue siendo una constante en la vida política nacional, que se reactiva de manera vigorosa durante los procesos electorales. Como fue notable en el pasado proceso electoral 4 de junio de 2017- en el Estado de México.

Respecto a las comunidades que se visibilizaron, como lo ha hecho notar Agustín Ávila (2008), en varias ocasiones, la Suprema Corte de Justicia de la Nación (SCJN), luego de las controversias impuestas por organizaciones indígenas e incluso por varios estados de la república, resolvió en cuanto al reconocimiento de derechos sociales que la ley era la base — "piso" - y no el límite — "techo"—, sobre la cual las legislaciones de los estados podrían ampliar de manera notable los derechos de las comunidades y pueblos que estuvieran dentro de su jurisdicción. Tal fue el caso de San Luis Potosí y de Oaxaca que cuentan con dos de las legislaciones que reconocen más derechos a los grupos indígenas. En el caso de SLP, mediante la definición y utilización de criterios heterodoxos se elaboró el padrón de Pueblos y comunidades, lográndose incluir a una buena cantidad de pequeños agrupamientos, algunos insertos en áreas urbanas, de los que se tenía una vaga noticia de su precedente indígena.

\section{Indigenas integrados mediante organizaciones de productores}

Entre estos dos extremos aparece una amplia gama de comunidades y grupos - u organizaciones - que ya se reconocían y reivindicaban como indígenas y que de hecho - $\mathrm{O}$ de facto - mantienen procesos autonómicos, desde antes de la promulgación de la ley indígena, en ciertas áreas de su cultura y organización y que han ofrecido una 
infinidad de respuestas. Se trata de la gran mayoría de comunidades y organizaciones reconocidas que se asientan en las distintas regiones étnicas del país. En este caso es la solidez de su organización social y política, lo que les permite mantener negociaciones con distintos actores como el Estado, partidos, incluso empresas y agencias internacionales. Sus formas de participación no se limitan a programas sociales, también lo hacen mediante grupos organizados de productores, por ejemplo, intervienen en negocios o redes de distribución de sus productos -incluso internacionales, como algunas cafetaleras- La gran mayoría de estas comunidades y organizaciones cuentan con una amplia experiencia organizativa. Abarcaría desde los municipios autónomos y comunidades con empresas forestales de Oaxaca y algunas de Michoacán, hasta una serie de organizaciones y comunidades que buscan, sin romper con las estructuras nacionales, reacomodarse en los espacios nacional y global. Están los múltiples casos de comunidades con empresas forestales (como las que ha estudiado Cl. Garibay, 2008), pero también otras que de manera clara vinculan los proyectos productivos y la gestión social con el fortalecimiento de su identidad y autonomía en ciertos aspectos que consideran fundamentales - como su territorio o su sistemas de autoridad y prestigio-; tal sería el caso de Cherán, Sevina o Tingambato en Michoacán, pero también bastantes Chiapanecas como San Juan Chamula, Zinacantán, Ocosingo entre otros o Cuetzalan y sus comunidades vecinas en Puebla. Sin duda su proximidad con el mercado capitalista las coloca en cierto nivel de riesgo, como ocurre ahora con las comunidades cafetaleras chiapanecas - el precio presenta fuertes variaciones y con frecuencia tiende a caer, además de que una plaga se extiende por algunas zonas de cultivo-. Por el lado de las organizaciones, las respuestas están marcadas en gran medida por la historia particular de sus conflictos, en el ámbito regional, como por la búsqueda de solución a problemas inmediatos o acuciantes y solo en pocos casos por proyectos de más largo aliento.

En la actualidad entre la gran diversidad de organizaciones, encontramos desde las que tratan de defender un proyecto autónomo propio, — como las grandes y medianas organizaciones de productores chiapanecos y oaxaqueños- si bien sobrellevado con muchísimas 
dificultades, hasta las que continúan estrechamente vinculadas a las organizaciones partidistas e incluso a los gobiernos en turno - como San Juan Chamula, ahora, en el 2015, dividido políticamente, porque de ser "orgullosamente priistas", como dicen los grandes letreros en la comunidad, por influencia del gobernador tienen un ayuntamiento del partido Verde Ecologista-. Todas de una u otra manera negocian con el Estado y las instancias políticas y financieras la autonomía de diversos aspectos de su organización social.

Entre estos grupos, las reformas, así como han abierto posibilidades para la consolidación de proyectos autónomos, como ha sido el caso de Cherán y varias comunidades oaxaqueñas, chiapanecas, poblanas, guerrerenses, también han permitido el empoderamiento de ciertos grupos políticos e intermediarios, de distinto signo político, al interior de las comunidades. Como sucede en gran parte de las comunidades oaxaqueñas, en las que bajo el lema de "usos y costumbres", según Recondo (2007) operan grupos de poder vinculados al Partido Revolucionario Institucional (PRI). En la mayoría de los casos han profundizado su dependencia hacia el mercado, al acentuar el desarrollo de proyectos "productivos", sea el fomento artesanal o de eco o etno turismo. Como ocurre a lo largo de la franja selvática de Chiapas en la frontera con Guatemala, en la que abunda la oferta de sitios ecoturísticos.

Es claro que la reforma nacional indígena estuvo subordinada a las llamadas reformas estructurales que desde principios de la década de los noventa se han venido implementando en el país. Entre ellas el apoyo y fomento a las actividades empresariales en particular las extractivas como la minería a cielo abierto. Las reformas indígenas de los estados adolecen de lo mismo, difícilmente otorgan una mayor soberanía a las comunidades sobre su territorio y sus recursos naturales, más allá de lo planteado en las leyes nacionales. Aunque en 2016, la CNDH emitió La Recomendación General (27/2016), en la que señala la obligatoriedad de la consulta a los pueblos y comunidades indígenas para el desarrollo de cualquier proyecto que las afecte. En estas comunidades, ha sido a partir del desarrollo de proyectos propios como han alcanzado cierta autodeterminación. 
Sin duda la diversidad ha crecido, se han visibilizado grupos y comunidades que por un buen tiempo trataron de no ser reconocidos como indígenas y ahora lo asumen, incluso han aparecido algunas nuevas categorías étnicas. Comunidades minúsculas, algunas ya integradas a las urbes, que no se hacían visibles pero que al otorgarles cierto reconocimiento establecen sus fronteras con respecto a sus vecinos, adscribiéndose a una categoría aparte. Y en otros casos se ha logrado redirigir el sentido del cambio social a nivel local, en cuanto se le dedica más recursos y esfuerzos a proyectos locales, sean desde el fortalecimiento de los sistemas de autoridad, hasta la organización ritual o la defensa del territorio comunal mediante la creación —institucionalizaciónde guardias armados.

Con excepción de las comunidades zapatistas autónomas — los llamados "caracoles" - las demás, así como se les han abierto posibilidades también enfrentan grandes retos, al menos en los temas de la gestión y el control de la violencia. Ambos íntimamente relacionados con la posibilidad de conservar y controlar sus recursos y territorio.

\section{Comentarios finales}

Ya se ha denunciado hasta el cansancio el carácter neoliberal de las reformas así como sus posibles consecuencias negativas, sobre todo para las poblaciones rurales, en cuanto las deja prácticamente en desamparo y sus recursos a merced del mercado. De hecho desde principios del nuevo siglo, Nigh (2001: 241) había señalado que "las leyes, tanto a nivel federal como estatal, no ofrecen mucho en términos de instrumentos jurídicos concretos para la defensa de los recursos naturales en los territorios indígenas. (...) tampoco despiertan mucha esperanza de que las comunidades pudieran proteger su patrimonio natural de los daños impulsados por intereses ajenos en nombre del desarrollo regional”.

Dada la interdependencia que existe entre los distintos sistemas económicos, en la actualidad todas las comunidades requieren de recursos, incluso para desarrollar proyectos contrahegemónicos o de resistencia al neoliberalismo. Como señala Santos (2009), el actual no es tiempo de respuestas fuertes o radicalmente alternativas a las que nos ofrece la 
globalización y sus marcos jurídicos, solo podemos conformarnos con respuestas "débiles débiles" o "fuertes débiles". Estas últimas constituirían propuestas medianamente alternativas, que partirían de los recursos jurídicos que ofrece el neoliberalismo multiculturalista, pero que no seguirían estrictamente el patrón esperado por el sistema. Casos similares, aunque referidos a otras latitudes son los que presenta Appadurai (2013). Se trata de organizaciones de pobres urbanos que se organizan para lograr financiamiento y desarrollar proyectos de vivienda popular en Mumbai, India. La respuesta organizativa de estos grupos, en esta ciudad que tiende a despojarlos y desplazarlos, representa para este autor una alternativa al modelo de desarrollo e integración propuesto por el neoliberalismo. Un argumento que representa una continuación de lo que había planteado en 1996, respecto a la importancia de la producción de localidad en el contexto global.

En este sentido se puede pensar en el desarrollo de ciudadanías y autonomías locales y fortalecimiento de la organización social, entre otros temas, como posibilidades que resultan de la gestión de recursos y su "buen" manejo. Desde los ańos noventa, la gestión de recursos aparece frecuentemente vinculada al prestigio social, a la par o incluso por encima de los cargos civiles y religiosos. Los nuevos intermediarios indígenas (de que habla De la Peña, 2006), serían estos gestores de proyectos comunales que además logran presentar una imagen de "honestidad" y compromiso en el manejo de recursos frente a su comunidad. Hay ejemplos claros de reinversión en capacitación, reforestación, programas de apoyo interno a ancianos, becas, programas educativos o formativos propios. Por ejemplo, muchas de las propuestas de las organizaciones de mujeres indígenas, refieren a mejorar las condiciones de vida en su familia y comunidad lo que vinculan con el tema del patriarcalismo y el sistema de autoridad que les inhibe su pleno desarrollo y las somete a relaciones de dominio que se traducen en su sobreexplotación (Baltazar, 2011). De ahí que su participación en redes, grupos y organizaciones que operan a nivel regional, nacional o internacional, para obtener financiamiento para proyectos de capacitación, productivos o de otro tipo, se haya convertido en una opción para lograr una participación más directa en los asuntos locales, incluso en la redefinición de las tareas 
de género al interior de las familias. Como lo muestran algunas historias de vida de mujeres que han participado en grupos y asociaciones en Zapotitlán Salinas o de Cuetzalan, Puebla, o las múltiples cooperativas en Chiapas, Michoacán, Oaxaca.

Se ha dicho, en múltiples ocasiones, que el actual modelo profundiza la dependencia de los recursos externos, principalmente federales y que también por su énfasis en la competitividad y la "eficiencia”, excluye a grandes capas de la población. En efecto, también provoca la sobre especialización en ciertas prácticas productivas, como los monocultivos que acaban con la diversidad ecológica. No obstante encontramos una buena cantidad de comunidades involucradas en estos procesos. Elaborar proyectos, "bajar recursos", sobre todo de las distintas agencias gubernamentales y "simular" su correcta aplicación a la hora de informar, también es una práctica recurrente en diferentes comunidades — se sabe de antemano que la inversión se irá a "fondo perdido"- Las historias de proyectos "fracasados", sean efímeros o que se mantienen estancados, son quizá más numerosas que la de los exitosos. De ahí que los discursos sobre frustración, desencanto o desconfianza, se mantengan y provoquen otro tipo de respuestas como la migración o la renovación de los conflictos faccionales. El manejo poco claro de fondos internacionales para proyectos fue una de las razones de la división de la Organización de la Nación Purhépecha en los años noventa; la disputa por el control de los recursos comunales - financieros o naturales- sería, según una tesis reciente (Román, 2015) una de las interpretaciones que se le da a la emergencia del movimiento por la autonomía en Cherán; y, en algunos casos a la defensa, por caciques locales, del régimen de "usos y costumbres" en Oaxaca.

Si consideramos que el Estado contemporáneo, no es el único generador de orden o el único que puede garantizar el orden social, aunque todavía sigue teniendo un papel importante en la adecuación de los requerimientos del mercado y en la delimitación de las políticas sociales en el territorio nacional y ahora en seguridad, entonces las pequeñas acciones que tienden hacia el fortalecimiento de la vida en comunidad adquieren otro sentido. Incluso aquellas que están fuera del ámbito de lo político y buscan fortalecer sistemas de fiestas y cargos religiosos. 
El capitalismo neoliberal, como es claro, no avanza solo protegido por leyes o convenios internacionales, sino también por medios informales e incluso ilegales. Por ejemplo cuando trata de apropiarse de bienes como minas, bosques, selva, agua. Su rostro promotor de la diversidad mediante el apoyo a proyectos productivos es el amable, y oculta al depredador, ilegal y violento. El Estado moderno no le ha podido hacer frente prácticamente en ningún país occidental ${ }^{7}$. De ahí que las comunidades locales — sean de base étnica o religiosa-, dispersas, con proyectos divergentes entre sí, se mantengan como una posibilidad organizativa más vital y persistente que las instituciones de la modernidad. Éstas, como la democracia representativa, los partidos políticos o las estructuras de gobierno, también han sido socavadas por el rostro oscuro del neoliberalismo. De tal manera que se muestran incapaces de dar respuestas definitivas a los retos que plantea el reconocimiento de la diversidad étnica en la actualidad. El Estado es un actor bastante debilitado con el que difícilmente se pueden negociar prerrogativas sociales. El mercado, por su parte, genera diversidad, pero no reconocimiento o solo el reconocimiento que ofrece el capital mediante la conversión de los bienes sociales en mercancías. Parecería entonces que la alternativa es el reforzamiento de la soberanía o autodeterminación comunal es decir: la toma de decisiones colectivas con responsabilidad. Al menos las comunidades con proyectos autogestivos propios, hacen descansar su viabilidad en el manejo responsable. Independientemente de que en la gran

\footnotetext{
${ }^{7}$ Es más en varios temas el Estado y los grupos ilegales actúan de manera conjunta, como en el del narcotráfico Según L. Astorga (entrevista en Proceso 19-vii-15) El narcotráfico en México creció al amparo del Estado, desde principios de siglo y fue hacia 1985, cuando los pactos y arreglos entre políticos y narcotraficantes comenzaron a cambiar. Tanto porque el Estado empezó a fragmentarse - y en cierta medida a perder soberanía- y también porque el narco empezó a crecer. Dice que en realidad los dos campos —el del Estado y la política, como el del narco- se transformaron. En tanto en las naciones industrializadas del norte del planeta ha crecido la informalidad, el crimen organizado, la ilegalidad y se han debilitado las instituciones democráticas, así como los valores universales que le daban sentido, Comaroff y Comaroff (2013) consideran que esos procesos ya se vivieron e instalaron en África y en gran parte de las naciones del sur, por lo que proponen que en la actualidad, las sociedades indutriales "avanzadas" están en realidad evolucionando hacia el modelo del sur, es decir, hacia la africanización.
} 
mayoría de las comunidades existan divisiones que lleven a críticas por envidias, chismes y, en ocasiones, enfrentamientos. Finalmente no hay que olvidar que la autonomía tiene que ver básicamente con la toma de decisiones y la toma de decisiones siempre ocurre dentro de marcos morales específicos (como lo ha señalado Ch. Taylor, 1996). La autonomía puede ejercerse en todos los niveles y de muchas maneras, desde el individual hasta el de amplias comunidades imaginarias.

Assies a fines de los noventa señalaba que las reformas neoliberales habían transformado la relación entre el mercado, el estado y la sociedad civil. Ahora tenemos claro que el Estado ha perdido soberanía y el control de muchas de sus funciones sociales - como la misma seguridad, ciertos territorios, garantizar medios de reproducción para sus ciudadanos, etc. - el mercado ha ganado mucha mayor presencia, incluso en áreas antes no consideradas de su incumbencia, mientras que la sociedad civil se ha fragmentado de manera notable. Por consiguiente el destino de los procesos autonómicos en contextos o situaciones de pluralidad jurídica, donde existen intereses y marcos morales en conflicto y donde el derecho no se aplica igual a todos, con un Estado débil, depende tanto de la acción de las mismas comunidades, como del mismo Estado. Hasta ahora tampoco ha podido garantizar mínimamente las condiciones para que las diferencias étnicas se expresen en condiciones de igualdad. En una sociedad fragmentada este podría ser el piso jurídico mínimo para que se expresen las diferencias en lo que queda de la unidad nacional.

\section{Bibliografía citada}

Appadurai, Arjun, 1996, Modernity at Large: cultural Dimensions of globalization, University of Minnesota Press, Minneapolis and London.

Appadurai, Arjun, 2013, The Future as Cultural Fact. Essays on the global condition, Verso, London and New York.

Assies, Willem, Gemma van der Haar y André Hoekema (editores), 1999, El reto de la diversidad, El Colegio de Michoacán, México. 
Baltazar, Raquel, 2011, Economía étnica. El papel de las organizaciones productivas en la construcción de ciudadanias locales, Tesis de doctorado, el Colegio de Michoacán, México.

Bengoa, José, 2000, La emergencia indígena en América Latina, Fondo de Cultura Económica, México.

CNDH, 2016, Recomendación General, no. 27/2016, sobre el derecho a la consulta previa de los pueblos y comunidades indigenas de la República Mexicana, DOF: 12/08/2016.

Comaroff, Jean y John Comaroff, 2013, Teoría desde el sur. O cómo los paises centrales evolucionan hacia África, Siglo XXI, Argentina.

De la Peña, Guillermo, 1999, “Territorio y ciudadanía étnica en la nación globalizada”, Desacatos, núm. 1, México, pp. 13-26.

De la Peña, Guillermo, 2006, "Los nuevos intermediarios étnicos, el movimiento indígena y la sociedad civil: dos estudios de caso en el Occidente mexicano", en E. Dagnino, A. Olvera y A. Panfichi, (coordinadores), La disputa por la construcción democrática en América Latina, FCE, CIESAS, UV, México, pp. 501-531.

Devillard, Marie José y Alejandro Baer, 2010, "Antropología y derechos humanos: multiculturalismo, retos y resignificaciones", Revista de Antropología Social, núm. 19, pp. 25-51.

Garibay, Claudio, 2008, Comunalismos y liberalismos campesinos, El Colegio de Michoacán, México.

Gasparello, Giovana, 2014, Autonomía indigena, violencia y justicia, Tesis de doctorado, UAM-I, Ciudad de México.

Leal, Olivia, 2014, Los chilas de Cuautepec, Tesis de doctorado, El Colegio de Michoacán, México.

Leyva, Xochitl y Araceli Burguete (coordinadoras), 2007, La remunicipalización de Chiapas. Lo politico y la política en tiempos de contrainsurgencia, CIESAS, Porrúa, México.

López, Francisco, 2010, San Juan Copala. De la rebelión de Hilarión a la formación del municipio autónomo, Centro de Orientación y Asesoría a Pueblos Indígenas, México.

Mora, Mariana, 2013, "La politización de la justicia zapatista frente a la guerra de baja intensidad en Chiapas”, en María Teresa, Sierra, Rosalva Aída Hernández y Rachel Sieder (editoras), 
Justicias indigenas y Estado. Violencias contemporáneas, Flacso, CIESAS, México.

Nigh, Roland, 2001, "Legislación indígena y recursos naturales", en Lourdes de León (coordinadora), 2001, Costumbres, leyes y movimiento indio en Oaxaca y Chiapas, CIESAS, Porrúa, México.

Paredes, Carlos y Jorge Martínez (coordinadores), 1012, ...Alzaban banderas de papel. Los pueblos originarios del Oriente y la Tierra Caliente de Michoacán, CDI, Morelia, Michoacán.

Recondo, David, 2007, La política del gatopardo. Multiculturalismo y democracia en Oaxaca, CIESAS, México.

Roman, Denise, 2014, El espejismo del orden. Etnografía histórica sobre política local en Cherán, Michoacán (1856-2014), Tesis de doctorado, El Colegio de Michoacán, México.

Santos, Boaventura de S., 2009, Sociología jurídica critica, editorial Trotta, Madrid.

Sierra, Teresa, 2006, "La renovación de la justicia indígena en tiempos de derechos. Etnicidad, género y diversidad", en Ruth Stanley (coordinadora), Estado, violencia y ciudadanía en América Latina, Vervuet, Frankfurt, Madrid.

Taylor, Charles, 1996, Las fuentes del yo. La construcción de la identidad moderna, Paidós, Madrid.

Taylor, Charles, 2009, El multiulturalismo y "la politica del reconocimiento", FCE, México.

Vázquez, Rodolfo, 2001, Liberalismo, estado de derecho y minorías, Paidós, UNAM, México.

Yanes, Pablo, Virginia Molina, y Óscar González (coordinadores), 2004, Ciudad pueblos indigenas y etnicidad, UCM, Dirección General de Equidad y Desarrollo Social, México. 